\title{
Thermal Degradation Behaviour of Ni(II) Complex of 3,4-Methylenedioxaphenylaminoglyoxime
}

\author{
Emin Karapınar, ${ }^{1}$ Ilkay Hilal Gubbuk, ${ }^{2}$ Bilge Taner, ${ }^{2}$ Pervin Deveci, ${ }^{2}$ and Emine Ozcan ${ }^{2}$ \\ ${ }^{1}$ Department of Chemistry, Faculty of Arts and Sciences, Pamukkale University, 20070 Denizli, Turkey \\ ${ }^{2}$ Department of Chemistry, Faculty of Sciences, Selçuk University, 42031 Konya, Turkey \\ Correspondence should be addressed to Emin Karapınar; ekarapinar@pau.edu.tr
}

Received 4 July 2013; Accepted 6 September 2013

Academic Editor: Hakan Arslan

Copyright (c) 2013 Emin Karapınar et al. This is an open access article distributed under the Creative Commons Attribution License, which permits unrestricted use, distribution, and reproduction in any medium, provided the original work is properly cited.

\begin{abstract}
Thermal degradation behaviour of the $\mathrm{Ni}$ (II) complex of 3,4-methylenedioxaphenylaminoglyoxime was investigated by TG, DTA, and DTG at a heating rate of $10^{\circ} \mathrm{C} \mathrm{min}{ }^{-1}$ under dinitrogen. The acquired experimental data shows that the complex is thermally stable up to $541 \mathrm{~K}$. The pyrolytic decomposition process occurs by melting metal complex and metal oxide remains as final product. The energies of the reactions involved and the mechanism of decomposition at each stage have been examined. The values of kinetic parameters such as activation energy $(E)$, preexponential factor $(A)$ and thermodynamic parameters such as enthalpy $(\Delta H)$, entropy $(\Delta S)$, and Gibbs free energy $(\Delta G)$ are also evaluated.
\end{abstract}

\section{Introduction}

vic-Dioximes have attracted extensive attention for many years due to their interesting structural diversity and various potential applications in different areas. Their synthesis, characterization, spectroscopic properties, and reactivity have been the subject of many papers because of their rich physicochemical properties, reactivity patterns, and potential applications in many important chemical processes in the areas such as medicine [1], bioorganic systems [2], catalysis [3], and liquid crystals [4]. Transition metal complexes of vicdioxime ligands have been widely investigated as analytical reagents as models for biological systems like vitamin $B_{12}$ $[5,6]$.

Thermal behaviour of the transition metal derivatives with azomethines (Schiff bases, hydrazones, and oximes) is very important for the researcher in various branches of theoretical and technical chemistry [7-9]. The wellestablished thermogravimetric analysis (TG), derivative thermogravimetric analysis (DTG), differential thermal analysis (DTA), and derivative thermogravimetric scanning calorimetry (DSC) techniques have been reliably and widely used over many decades in studying thermal behaviour and properties of various types of materials and evaluating the thermal parameters for their degradation processes $[10,11]$. The thermal analysis of the compound gives information about its stability and suggests a decomposition pathway. Therefore, kinetic studies have become a crucial point in thermal analysis, in which the main purpose is to determine the mechanism(s) of pyrolysis reaction and to calculate the parameters of the Arrhenius equation.

The aims of this research are to study the chemical steps of the investigated degradation and the evaluation of the kinetic and thermodynamic parameters by using (Coats-Redfern) CR, (Horowitz-Metzger) HM, (Van Krevelen) VK, (Broido) $B$, and (Madhusudanan-Krishnan-Ninan) MKN methods for each step and to obtain degradation kinetics data.

\section{Experimental}

All the reagents purchased from Merck, Fluka, or Sigma and materials were chemically pure. The vic-dioxime complex was synthesized from analytical pure reagents as described in the literature [12]. Elemental analysis $(\mathrm{C}, \mathrm{H}$, and $\mathrm{N}$ ) was performed on a LECO-932 CHNSO apparatus. The IR spectra were recorded with a Perkin Elmer Model 1605 FTIR spectrophotometer from $\mathrm{KBr}$ pellets. ${ }^{1} \mathrm{H} \mathrm{NMR}$ and ${ }^{13} \mathrm{C}$ NMR spectra were recorded on Bruker GmbH Dpx-400 MHz 


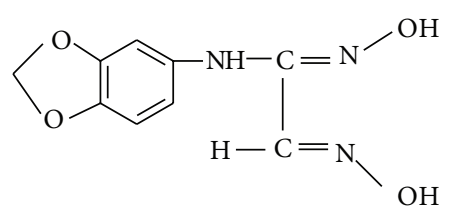

HL

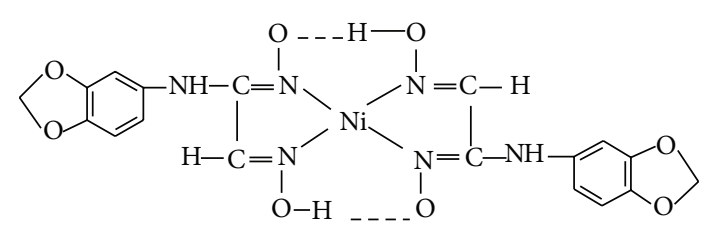

$\mathrm{Ni}(\mathrm{HL})_{2}$

Figure 1: Presentation of $\mathrm{HL}, \mathrm{Ni}(\mathrm{HL})_{2}$.

high-performance digital FT-NMR spectrometers in DMSO$\mathrm{d}_{6}$. The thermal measurements were carried out on a Perkin Elmer SII-Diamond TG-DTA Instruments thermal analysis system in dinitrogen atmospheres, applying a heating rate of $10^{\circ} \mathrm{C} \mathrm{min}^{-1}$ in a temperature range of $313-1173 \mathrm{~K}$. Sample mass was $2.675 \mathrm{mg}$.

\section{Results and Discussion}

3.1. Elemental Analysis, IR, ${ }^{1} \mathrm{H} N M R$, and ${ }^{13} C \mathrm{NMR}$ Spectra. The structure of 3,4 methylenedioxaphenylaminoglyoxime $(\mathrm{HL})$ and $\mathrm{Ni}(\mathrm{II})$ complex of this ligand $\left(\mathrm{Ni}(\mathrm{HL})_{2}\right)$ are shown in Figure 1. $\mathrm{HL}$ and $\mathrm{Ni}(\mathrm{HL})_{2}$ were characterized by elemental analysis, IR, ${ }^{1} \mathrm{H}$ NMR, and ${ }^{13} \mathrm{C}$ NMR spectra [11]. ${ }^{1} \mathrm{H}$ NMR and ${ }^{13} \mathrm{C}$ NMR spectra of $\mathrm{Ni}(\mathrm{HL})_{2}$ are given in Figures 2(a) and $2(\mathrm{~b})$.

The elemental analyses of $\mathrm{HL}$ and $\mathrm{Ni}(\mathrm{HL})_{2}$ were in agreement with theoretical expectations as given in the literature [12]. In the FTIR spectra of vic-dioxime complexes, the most important absorption bands that belong to the various vibration frequencies of the oxime groups are $\nu_{\mathrm{OH}}$ : $3368-3398 \mathrm{~cm}^{-1}$ (broad band), $v_{\mathrm{C}=\mathrm{N}}: 1610-1640 \mathrm{~cm}^{-1}$, and $\nu_{\mathrm{N}-\mathrm{O}}: 960-970 \mathrm{~cm}^{-1}$ (a single band). The ${ }^{1} \mathrm{H}$ and ${ }^{13} \mathrm{C}$ NMR spectra were obtained in DMSO for the complex. In the ${ }^{1} \mathrm{H}$ NMR spectra of $\mathrm{Ni}(\mathrm{HL})_{2}$, the proton resonance signal of the intermolecular hydrogen bridge appeared at $14.6 \mathrm{ppm}$, and the chemical shifts belonging to free $\mathrm{OH}$ protons (around $10 \mathrm{ppm}$ ) were not observed. In the ${ }^{13} \mathrm{C}$ NMR spectra, quaternary carbon signals of hydroximino carbon atom $(\mathrm{C}=\mathrm{N}-\mathrm{O})$ appeared at around $147 \mathrm{ppm}$ (Figures 2(a) and 2(b)).

3.2. Thermal Behaviours of the Metal Complex. In the present study, thermal behaviour of the $\mathrm{Ni}(\mathrm{HL})_{2}$ was studied with TG, DTA, and DTG techniques. Figure 3 shows TG, DTA, and DTG curves of the complex.

From the thermogram, it can be observed that a threestep thermal degradation process exists for $\mathrm{Ni}(\mathrm{HL})_{2}$. The thermal degradation for $\mathrm{Ni}(\mathrm{HL})_{2}$ is shown in Scheme 1 .

For this complex, the first stage of degradation began at $541 \mathrm{~K}$ and terminated in $581 \mathrm{~K}$, and the observed mass loss was $44.58 \%$, which corresponds to the loss of $\mathrm{CH}_{2} \mathrm{O}_{2} \mathrm{C}_{6} \mathrm{H}_{3} \mathrm{NHCN}$, and $2 \mathrm{OH}$, NO molecules. The second stage of degradation, between 612 and $857 \mathrm{~K}$, resulted in $29.98 \%$ weight loss. The third stage of degradation occurred in temperature range of $889-1078 \mathrm{~K}$. In last two stages, $\mathrm{CH}_{2} \mathrm{O}_{2} \mathrm{C}_{6} \mathrm{H}_{3} \mathrm{NCH}$ and $2 \mathrm{CHN}$ molecules were lost from the complex, respectively. The stages of degradation were summarized in Table 1.

It can be seen clearly (Table 1) that the mass losses obtained from the TG curves and that calculated for the corresponding molecule or molecules and final decomposition product (i.e., final residue) are in good agreement for all of the decomposition steps. Thermal degradation studies of the $\mathrm{Ni}(\mathrm{HL})_{2}$ indicated that this complex was thermally stable up to $541 \mathrm{~K}$ and continues degrading up to $1079 \mathrm{~K}$. The initial mass loss is seen to occur at $541 \mathrm{~K}$, and decomposition is seen to end with $85.28 \%$ mass loss at $1078 \mathrm{~K}$ with a greenishblack coloured solid $(\mathrm{NiO})$ in the TG curves. Degradation of this complex occurs in three stages and in harmony with the literature $[13,14]$.

The inflation of the t.g.a. curves of the complex at a temperature below $900^{\circ} \mathrm{C}$ indicates the decomposition of the fully organic part of the chelate, leaving the metallic oxide at the final temperature $[13,14]$.

3.3. Kinetic Studies. In order to determine kinetic parameters in a solid-state degradation reaction, usually several equations [15-17] have been proposed as means of analyzing a TG curve. In the kinetic studies of the thermal systems, the masstemperature relation, which can determine the behaviour of the degradation reactions, can be examined. In the present study, five equations such as HM [18], CR [19], VK [20], B [21], and MKN [22] were used for calculating the activation energy $(E)$, preexponential factor $(A)$, and thermodynamic parameters $(\Delta G, \Delta H$, and $\Delta S)$. The kinetics was studied for all the three stages of degradation of the complex. The degree of conversion, $\alpha$, is defined as the ratio of actual weight loss to total weight loss. $\alpha$ is calculated according to

$$
\alpha=\frac{W_{0}-W}{W_{0}-W_{f}},
$$

where $W_{0}$ is the initial mass of the sample (g), $W$ is the mass of the sample $(\mathrm{g})$ at a time and at temperature $T(\mathrm{~K})$, and $W_{f}$ is the final mass of the sample $(\mathrm{g})$. The rate of degradation process can be described as the product of two separate functions of temperature and fractional conversion [23]:

$$
\frac{d \alpha}{d t}=k(T) f(\alpha)
$$

where $\alpha$ is the fraction decomposed at time $t, k(T)$ is the temperature dependent function, and $f(\alpha)$ is the conversion 


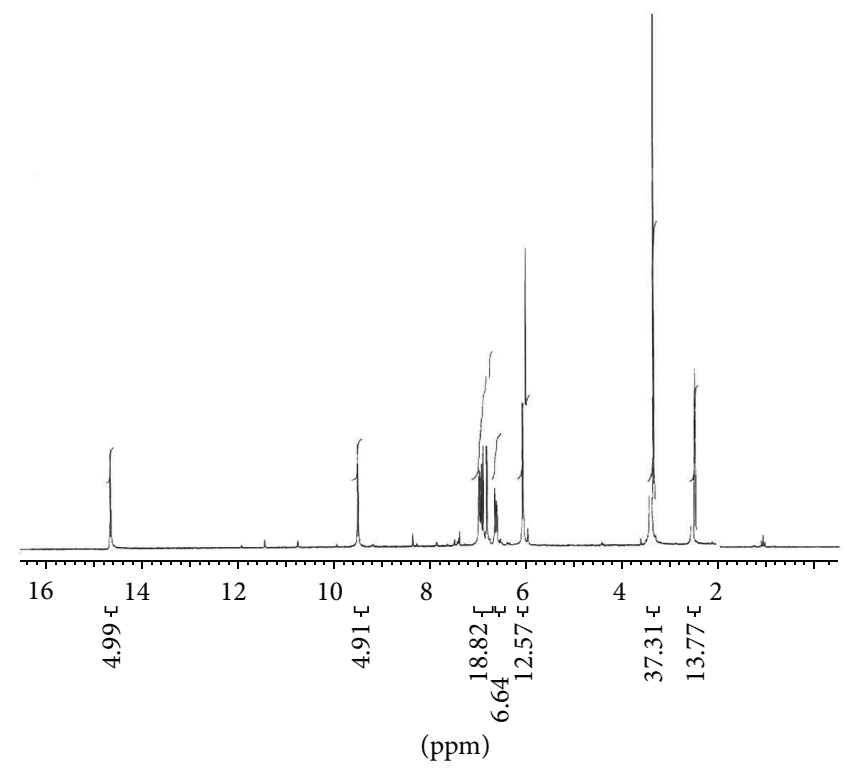

(a)

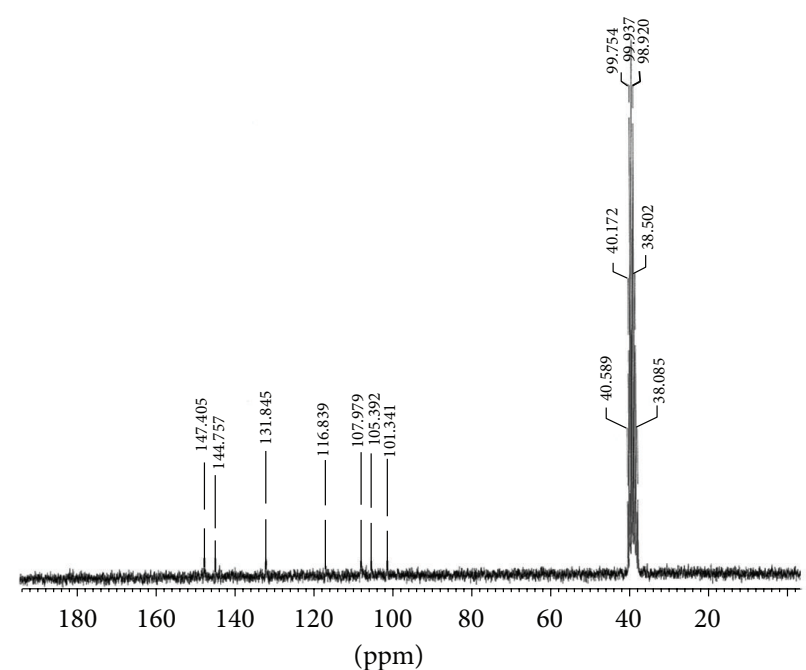

(b)

Figure 2: (a) ${ }^{1} \mathrm{H}$ NMR spectra of the $\mathrm{Ni}(\mathrm{HL})_{2}$; (b) ${ }^{13} \mathrm{C}$ NMR spectra of $\mathrm{Ni}(\mathrm{HL})_{2}$.

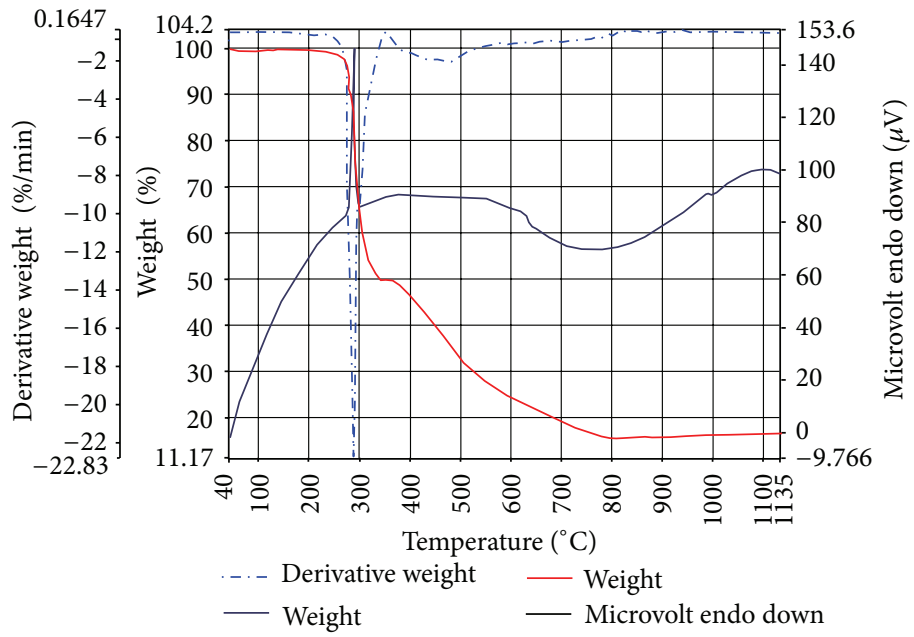

Figure 3: TG/DTA/DTG plots for $\mathrm{Ni}(\mathrm{HL})_{2}$ complex.

function dependent on the mechanism of degradation:

$$
\begin{gathered}
k(T)=A \exp \left(-\frac{E}{R T}\right), \\
f(\alpha)=(1-\alpha)^{n} .
\end{gathered}
$$

Then,

$$
\frac{d \alpha}{d t}=A \exp \left(-\frac{E}{R T}\right)(1-\alpha)^{n}
$$

According to Horowitz-Metzger method [18] for $n=1$ ( $n$ is the reaction order),

$$
\log [g(\alpha)]=\frac{E \theta}{2.303 R T_{m}^{2}}
$$

Here, $R$ is the gas constant and $\theta=T-T_{m}$, where $T_{m}$ is the temperature of maximum reaction rate and $T$ is the temperature in Kelvin at any instant. A plot of $\log [g(\alpha)]$ versus $\theta$ (Figure 4 ) should give a straight line whose slope is $E / R T_{m}^{2}$ [24]. $g(\alpha)=-\ln (1-\alpha)$ indicates random nucleation model for the degradation of the material. The preexponential factor $(A)$ is calculated by using (6):

$$
A=\frac{E}{R T_{m}^{2}} \beta \exp \left(\frac{E}{R T_{m}}\right) .
$$

Here, $\beta$ is the heating rate $\left(\mathrm{K} \mathrm{min}^{-1}\right)$.

According to Coats-Redfern method [19],

$$
\log \left[\frac{g(\alpha)}{T^{2}}\right]=\log \left[\frac{A R}{\beta E}\left(1-\frac{2 R T}{E}\right)\right]-\frac{E}{2.303 R T} \text {. }
$$




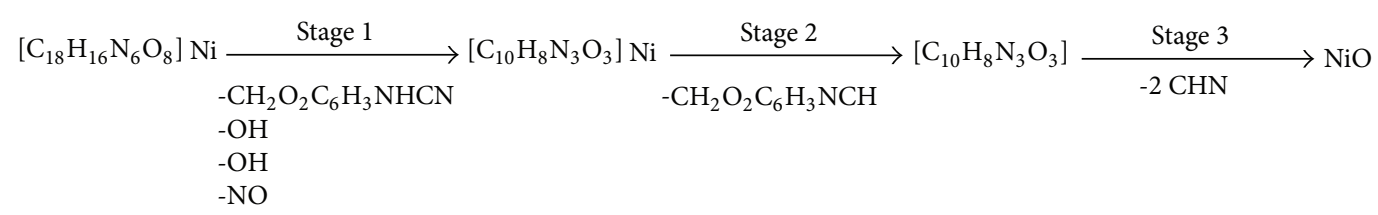

SCHeme 1: The thermal degradation for $\mathrm{Ni}(\mathrm{HL})_{2}$.

TABLE 1: The temperature range $T / \mathrm{K}$ and weight loss values of the degradation stages for the $\mathrm{Ni}(\mathrm{HL})_{2}$.

\begin{tabular}{|c|c|c|c|c|c|c|}
\hline \multirow{2}{*}{ Compound } & \multirow{2}{*}{ Stage } & \multirow{2}{*}{$T / \mathrm{K}$} & \multirow{2}{*}{ Evolved moieties } & \multicolumn{3}{|c|}{ Weight loss (\%) } \\
\hline & & & & Found & Calc. & $\mathrm{RE}(\%)$ \\
\hline \multirow{4}{*}{$\mathrm{Ni}(\mathrm{HL})_{2}$} & 1st & $541-581$ & $\mathrm{CH}_{2} \mathrm{O}_{2} \mathrm{C}_{6} \mathrm{H}_{3} \mathrm{NHCN}, 2 \mathrm{OH}, \mathrm{NO}$ & 44.58 & 44.96 & 0.85 \\
\hline & 2nd & $612-857$ & $\mathrm{CH}_{2} \mathrm{O}_{2} \mathrm{C}_{6} \mathrm{H}_{3} \mathrm{NCH}$ & 29.98 & 29.44 & 1.83 \\
\hline & $3 \mathrm{rd}$ & 889-1078 & $2 \mathrm{CHN}$ & 9.97 & 10.74 & 7.1 \\
\hline & Residue & $>1079$ & $\mathrm{NiO}$ & 15.42 & 14.72 & 4.75 \\
\hline
\end{tabular}

$\mathrm{RE}(\%)$ : \% relative error.

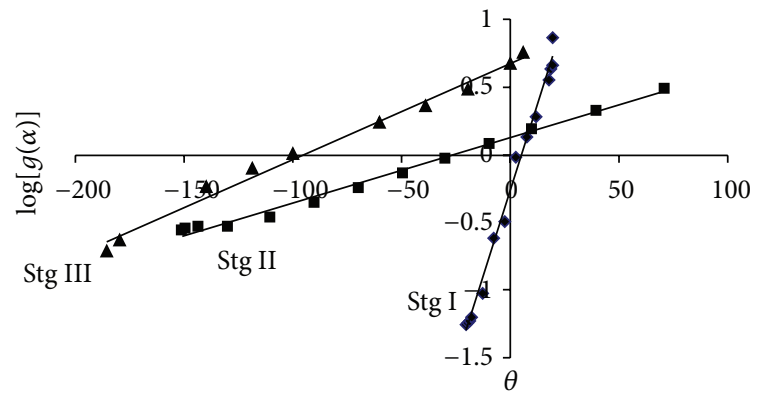

Figure 4: Graphical presentation of the $\log [g(\alpha)]-\theta$ plot of HM equation $\mathrm{Ni}(\mathrm{HL})_{2}$.

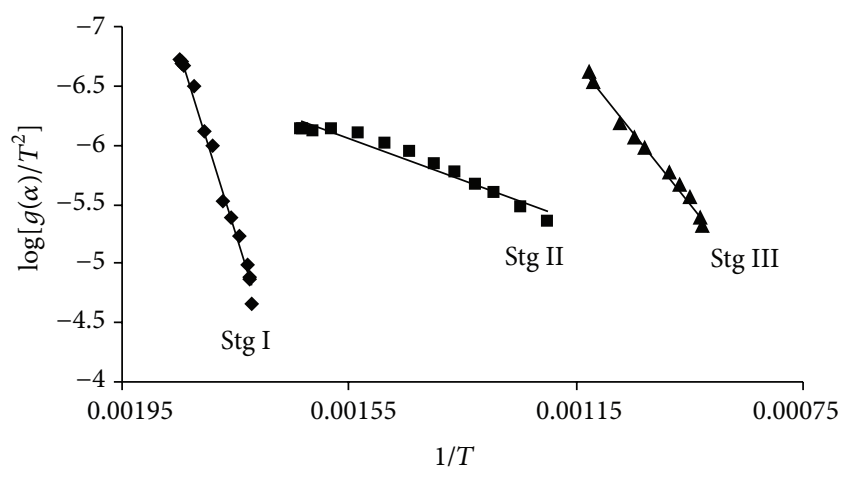

FIGURE 5: Graphical presentation of the $\log \left[g(\alpha) / T^{2}\right]-1 / T$ plot of CR equation of $\mathrm{Ni}(\mathrm{HL})_{2}$.

Plot of $\log \left[g(\alpha) / T^{2}\right]$ versus $1 / T$ (Figure 5) gives the slope for evaluation of $E$ and the intercept of $A$.

According to the Van Krevelen [20] method,

$$
\begin{aligned}
\ln [g(\alpha)]= & \ln \left[\frac{A}{\beta}\left(\frac{0.368}{T_{m}}\right)^{E / R T_{m}}\left(\frac{E}{R T_{m}}+1\right)^{-1}\right] \\
& +\left(\frac{E}{R T_{m}}+1\right) \ln T .
\end{aligned}
$$

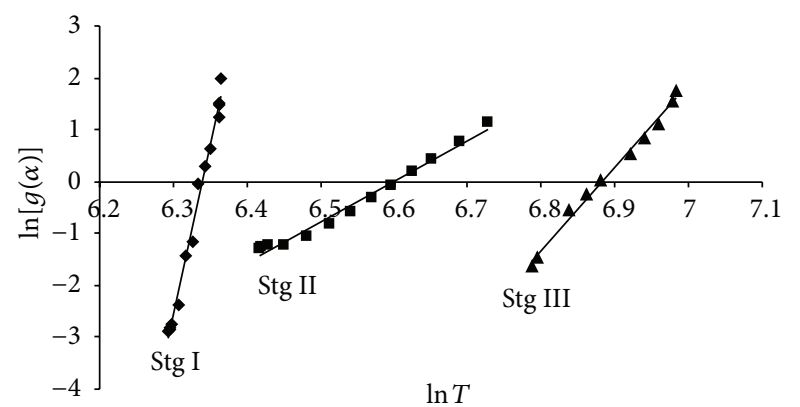

FIGURE 6: Graphical presentation of the $\ln [g(\alpha)]-\ln T$ plot of VK equation of $\mathrm{Ni}(\mathrm{HL})_{2}$.

A typical curve of $\log [g(\alpha)]$ versus $\ln T$ for the nickel(II) complex is shown in Figure 6. The activation energies calculated from the slopes of degradation for metal complex are listed in Table 2.

The mathematical expression of Broido's [21] method is

$$
\ln [g(\alpha)]=\ln \left[\frac{A}{\beta}\left(\frac{R}{E}\right) T_{m}^{2}\right]-\left(\frac{E}{R}\right) \times \frac{1}{T}
$$

$E$ can be calculated from the plot of $\log [g(\alpha)]$ versus $1 / T$ (Figure 7).

The final method of calculation of $E$ is developed by Madhusudanan-Krishnan-Ninan. According to the MKN equation [22] method,

$$
\begin{aligned}
\ln \left[\frac{g(\alpha)}{T^{1.921503}}\right]= & {\left[\ln \frac{A E}{\beta R}+0.3772050-1.921503 \ln E\right] } \\
& -0.1200394\left(\frac{E}{T}\right) .
\end{aligned}
$$

According to this method, the plot of $\ln \left[g(\alpha) / T^{1.921503}\right]$ versus $1 / T$ gives straight lines (Figure 8 ), and $E$ and $A$ can be calculated from the slope and intercept, respectively. 
TABLE 2: Kinetic parameters of $\mathrm{Ni}(\mathrm{HL})_{2}$ determined using the $\mathrm{CR}, \mathrm{HM}, \mathrm{B}, \mathrm{MKN}$, and VK equations.

\begin{tabular}{|c|c|c|c|c|c|c|c|}
\hline \multirow{2}{*}{ Complex } & \multirow{2}{*}{ Stage } & \multirow{2}{*}{ Method } & \multicolumn{5}{|c|}{ Parameter } \\
\hline & & & $E\left(\mathrm{~J} \mathrm{~mol}^{-1}\right)$ & $A\left(\mathrm{~s}^{-1}\right)$ & $\Delta S\left(\mathrm{~J} \mathrm{~mol}^{-1} \mathrm{~K}^{-1}\right)$ & $\Delta H\left(\mathrm{~kJ} \mathrm{~mol}^{-1}\right)$ & $\Delta G\left(\mathrm{~kJ} \mathrm{~mol}^{-1}\right)$ \\
\hline \multirow{15}{*}{$\mathrm{Ni}(\mathrm{HL})_{2}$} & \multirow{5}{*}{ 1st } & CR & $2.95 \times 10^{5}$ & $3.58 \times 10^{26}$ & $2.58 \times 10^{2}$ & $2.90 \times 10^{5}$ & $1.43 \times 10^{5}$ \\
\hline & & HM & $3.01 \times 10^{5}$ & $6.43 \times 10^{26}$ & $2.62 \times 10^{2}$ & $2.96 \times 10^{5}$ & $1.47 \times 10^{5}$ \\
\hline & & B & $3.04 \times 10^{5}$ & $1.54 \times 10^{12}$ & 2.33 & $2.99 \times 10^{5}$ & $2.98 \times 10^{5}$ \\
\hline & & VK & $3.03 \times 10^{5}$ & $5.48 \times 10^{30}$ & $3.38 \times 10^{2}$ & $2.98 \times 10^{5}$ & $1.10 \times 10^{5}$ \\
\hline & & MKN & $2.95 \times 10^{5}$ & $4.60 \times 10^{28}$ & $2.98 \times 10^{2}$ & $2.90 \times 10^{5}$ & $1.24 \times 10^{5}$ \\
\hline & \multirow{5}{*}{ 2nd } & $\mathrm{CR}$ & $4.01 \times 10^{5}$ & $3.81 \times 10$ & $-2.40 \times 10^{2}$ & $3.42 \times 10^{4}$ & $1.72 \times 10^{5}$ \\
\hline & & HM & $4.87 \times 10^{5}$ & $5.23 \times 10^{2}$ & $-2.19 \times 10^{2}$ & $4.23 \times 10^{4}$ & $1.58 \times 10^{5}$ \\
\hline & & B & $5.22 \times 10^{4}$ & $4.12 \times 10$ & $-2.21 \times 10^{2}$ & $4.63 \times 10^{4}$ & $2.01 \times 10^{5}$ \\
\hline & & VK & $5.06 \times 10^{4}$ & $3.73 \times 10^{5}$ & $-1.45 \times 10^{2}$ & $4.48 \times 10^{4}$ & $1.46 \times 10^{5}$ \\
\hline & & $\mathrm{MKN}$ & $4.05 \times 10^{4}$ & $2.98 \times 10^{3}$ & $-1.85 \times 10^{2}$ & $3.47 \times 10^{4}$ & $1.65 \times 10^{5}$ \\
\hline & \multirow{5}{*}{$3 \mathrm{rd}$} & $\mathrm{CR}$ & $1.04 \times 10^{5}$ & $4.35 \times 10^{4}$ & $-1.66 \times 10^{2}$ & $9.57 \times 10^{4}$ & $1.76 \times 10^{5}$ \\
\hline & & HM & $1.24 \times 10^{5}$ & $4.75 \times 10^{4}$ & $-1.65 \times 10^{2}$ & $1.16 \times 10^{5}$ & $1.77 \times 10^{5}$ \\
\hline & & B & $1.20 \times 10^{5}$ & $6.32 \times 10^{2}$ & $-2.01 \times 10^{2}$ & $1.11 \times 10^{5}$ & $3.13 \times 10^{5}$ \\
\hline & & VK & $1.24 \times 10^{5}$ & $7.23 \times 10^{8}$ & $-8.5 \times 10$ & $1.16 \times 10^{5}$ & $2.01 \times 10^{5}$ \\
\hline & & $\mathrm{MKN}$ & $1.04 \times 10^{5}$ & $1.20 \times 10^{6}$ & $-1.39 \times 10^{2}$ & $9.62 \times 10^{4}$ & $2.35 \times 10^{5}$ \\
\hline
\end{tabular}

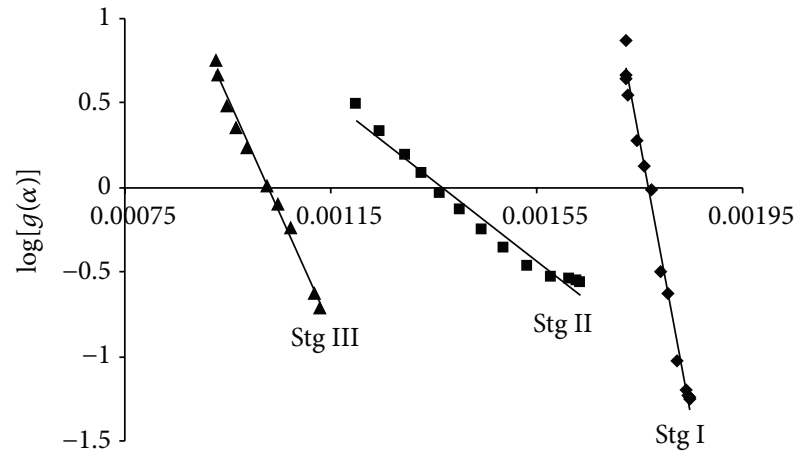

$1 / T$

Figure 7: Graphical presentation of the $\log [g(\alpha)]-1 / T$ plot of $B$ equation of $\mathrm{Ni}(\mathrm{HL})_{2}$.

The values obtained for $E$ and $A$ of $\mathrm{Ni}(\mathrm{HL})_{2}$ for each three stages have been calculated and are shown in Table 2.

The entropy of activation $\Delta S$ is calculated by using

$$
\Delta S=R \ln \left(\frac{A h}{k T_{m}}\right),
$$

where $k$ is the Boltzmann constant and $h$ is the Planck constant. The activation enthalpy, $\Delta H$, and Gibbs free energy, $\Delta G$, are calculated from (12):

$$
\begin{gathered}
\Delta H=E-R T, \\
\Delta G=\Delta H-T \Delta S .
\end{gathered}
$$

High activation energy values were calculated at the appropriate linear regions of the temperature range by using five methods and were given in Table 2 . The high $E$ values indicate that the ligand is strongly bonded to the $\mathrm{Ni}$ (II) ions [25]. The activation energy is obtained at nearly the same

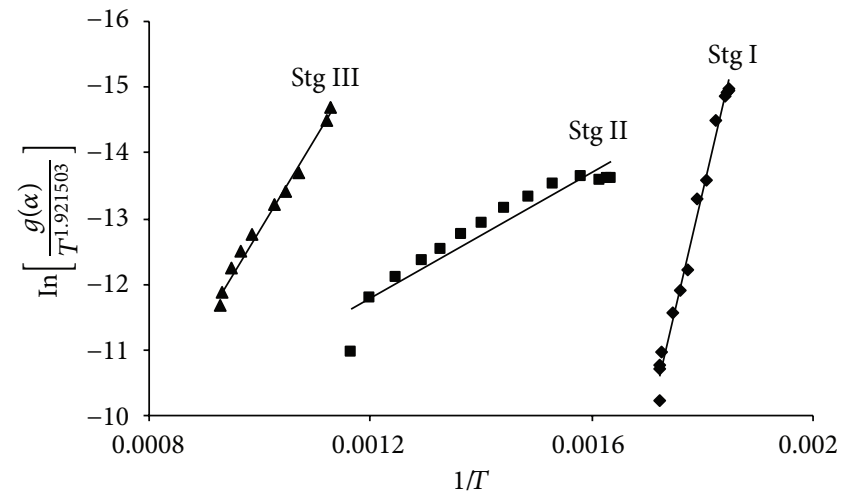

FIGURE 8: Graphical presentation of the $\ln \left[g(\alpha) / T^{1.921503}\right]-1 / T$ plot of MKN equation of $\mathrm{Ni}(\mathrm{HL})_{2}$.

value for three steps because of the structures of the evolved moieties.

In the 1st stage, entropy was found to be positive. So, the activated complex can be thought to own less ordered structures than the reactant [10]. The negative values of entropy in the 2 nd and 3 rd steps indicate that the reactions were slower than normal. The negative values of $\Delta S$ are due to low $A$ values and account for the nonspontaneous nature of the reaction [26]. The nonspontaneous nature of the degradation reactions of the complex was supported by the positive value of $\Delta G$ in the degradation steps [25]. The enthalpy was found to be positive value, and it was partially decreased with increase in temperature. The positive value of $\Delta H$ at a particular temperature indicated that the process was of endothermic nature. The high heat of degradation released during the processes might have masked the endothermicity of degradation reaction [17]. In general, it can be concluded that it is possible to obtain $\mathrm{Ni}(\mathrm{HL})_{2}$ with in thermal stability and more applicable from the economic viewpoint. 


\section{Conclusions}

The new complex, $\mathrm{Ni}(\mathrm{HL})_{2}$, was prepared for the first time, and it was presented in the literature [11]. The present work is the first ever report including the reaction mechanism of thermal decomposition and application of the theories, namely, CR, HM, VK, MKN, and B, for all the three stages of decomposition of the material. The TG curves show the mass decrease with the linear increase in temperature. The material released at each step of the decomposition was identified by attributing the mass loss $(\Delta m)$ at a given step to the component of similar weight calculated from the molecular formula of the investigated complex by comparing that with works of literature of relevant compounds taking into account their temperature $[15,27]$. The observed percentage of weight loss corresponding to various steps in the TG curves was compared with those calculated in the assumption of possible composition of the complex suggested from the elemental analysis and confirmed later from IR, ${ }^{1} \mathrm{H}-\mathrm{NMR}$, and ${ }^{13} \mathrm{C}$ NMR spectral studies. This may assist by identifying the mechanism of reaction in the decomposition steps. Tables 1 and 2 give the characteristic thermal and kinetic parameters of each step in the decomposition sequence of the complex, determined or evaluated, from the TG curves.

\section{Conflict of Interests}

All the authors declared that there are no financial relationships with Merck, Fluka, Sigma, or any other companies.

\section{Acknowledgments}

The authors thank the Scientific and Technical Research Council of Turkey (TUBITAK, Grant no. 108T655) and Selcuk University Research Foundation (SUBAP 08101031) for the financial support of this work.

\section{References}

[1] J. R. Dilworth and S. J. Parrott, "The biomedical chemistry of technetium and rhenium," Chemical Society Reviews, vol. 27, pp. 43-55, 1998.

[2] W. A. Wolkert and T. J. Hoffman, "Therapeutic radiopharmaceuticals," Chemical Reviews, vol. 99, pp. 2269-2292, 1999.

[3] P. Mitchell, "Keilin's respiratory chain concept and its chemiosmotic consequences," Science, vol. 206, no. 4423, pp. 1148-1159, 1979.

[4] K. Ohta, R. Higashi, M. Ikejima, I. Yamamoto, and N. Kobayashi, "Disk-like liquid crystals of transition metal complexes: part 21.-critical molecular structure change from columnar to lamellar liquid crystal in bis(diphenylglyoximato)nickel(II)-based complexes," Journal of Materials Chemistry, vol. 8, no. 9, pp. 1979-1991, 1998.

[5] F. J. Welcher, Organic Analytical Reagents, vol. 3, Van Nostrand, New York, NY, USA, 1947.

[6] N. Bresciani-Pahor, M. Forcolin, L. G. Marzilli, L. Randaccio, M. F. Summers, and P. J. Toscano, "Organocobalt B12 models: axial ligand effects on the structural and coordination chemistry of cobaloximes," Coordination Chemistry Reviews, vol. 63, pp. 1$125,1985$.
[7] Y. Miyazaki, T. Sakakibara, H. Miyasaka, N. Matsumoto, and M. Sorai, "Heat capacity and magnetic phase transition of twodimensional metal-assembled complex $\left(\mathrm{NEt}_{4}\right)\left[\mathrm{Mn}^{I I I}\right.$ (salen) $\left.{ }_{2} \mathrm{Fe}^{I I I}(\mathrm{CN})_{6}\right]$," Journal of Thermal Analysis and Calorimetry, vol. 81, no. 3, pp. 603-607, 2005.

[8] H. A. El-Boraey, "Structural and thermal studies of some aroylhydrazone Schiff's bases-transition metal complexes," Chemistry and Materials Science, vol. 81, no. 2, pp. 309-346, 2005.

[9] M. Lalia-Kantouri, "Factors influencing the thermal decomposition of transition metal complexes with 2-OH-aryloximes under nitrogen," Journal of Thermal Analysis and Calorimetry, vol. 82, no. 3, pp. 791-796, 2005.

[10] T. C. Chang, K. H. Wu, C. L. Liao, S. T. Lin, and G. P. Wang, "Thermo-oxidative degradation of siloxane-containing polyimide and unmodified polyimide," Polymer Degradation and Stability, vol. 62, no. 2, pp. 299-305, 1998.

[11] S. K. Arora, V. Patel, and A. Kothari, "Kinetics and mechanism of thermal decomposition of strontium tartrate crystals," Materials Chemistry and Physics, vol. 84, no. 2-3, pp. 323-330, 2004.

[12] B. Yildirim, E. Ozcan, and P. Deveci, "New glyoxime derivatives and their transition metal complexes," Russian Journal of Coordination Chemistry, vol. 33, no. 6, pp. 417-421, 2007.

[13] H. Arslan, N. Külcü, and A. I. Pekacar, "Thermal decomposition kinetics of anilino-p-chlorophenylglyoxime complexes of Cobalt (II), Nickel (II) and Copper (II)," Turkish Journal of Chemistry, vol. 27, no. 1, pp. 55-63, 2003.

[14] H. Arslan, "Cobalt, nickel and copper complexes of benzylamino- $p$-chlorophenylglyoxime thermal and thermodynamic data," Journal of Thermal Analysis and Calorimetry, vol. 66, no. 2, pp. 399-407, 2001.

[15] H. Arslan, N. Özpozan, and N. Tarkan, "Kinetic analysis of thermogravimetric data of p-toluidino-p-chlorophenylglyoxime and of some complexes," Thermochimica Acta, vol. 383, no. 1-2, pp. 69-77, 2002.

[16] H. Kumar, A. A. Kumar, and S. Siddaramaiah, "Physicomechanical, thermal and morphological behaviour of polyurethane/poly(methyl methacrylate) semiinterpenetrating polymer networks," Polymer Degradation and Stability, vol. 91, no. 5, pp. 1097-1104, 2006.

[17] A. H. M. Siddalingaiah and S. G. Naik, "Spectroscopic and thermogravimetric studies on $\mathrm{Ni}(\mathrm{II}), \mathrm{Cu}(\mathrm{II})$ and $\mathrm{Zn}$ (II) complexes of di(2,6-dichlorophenyl)carbazone," Journal of Molecular Structure, vol. 582, pp. 129-136, 2002.

[18] H. H. Horowitz and G. Metzger, "A new analysis of thermogravimetric traces," Analytical Chemistry, vol. 35, no. 10, pp. 14641468, 1963.

[19] A. W. Coats and J. P. Redfern, "Kinetic parameters from thermogravimetric data," Nature, vol. 201, no. 4914, pp. 68-69, 1964.

[20] D. W. Van Krevelen and P. J. Hoftyzen, Properties of Polymers, Elsevier Scientific, Amsterdam, The Netherlands, 2nd edition, 1980.

[21] B. A. Broido, "Simple, sensitive graphical method of treating thermogravimetric analysis data," Journal of Polymer Science Part A-2, vol. 7, no. 10, pp. 1761-1773, 1969.

[22] P. M. Madhusudanan, K. Krishnan, and K. N. Ninan, "New approximation for the $\mathrm{p}(\mathrm{x})$ function in the evaluation of nonisothermal kinetic data," Thermochimica Acta, vol. 97, pp. 189201, 1986.

[23] J. González, C. Albano, R. Sciamanna et al., "Dynamic thermal decomposition of blends of polyamide 6 with functionalized 
and non-functionalized PP," Polymer Degradation and Stability, vol. 68, no. 1, pp. 9-19, 2000.

[24] K. K. Bamzai and S. Kumar, "Studies on kinetics and mechanism of thermal decomposition of yttrium tartrate trihydrate crystals," Materials Chemistry and Physics, vol. 107, no. 2-3, pp. 200-207, 2008.

[25] I. T. Ahmed, "Thermal decomposition study on mixed ligand thymine complexes of divalent nickel(II) with dianions of some dicarboxylic acids," Journal of Analytical and Applied Pyrolysis, vol. 80, no. 2, pp. 383-388, 2007.

[26] D. Borah and M. K. Baruah, "Kinetic and thermodynamic studies on oxidative desulphurisation of organic sulphur from Indian coal at 50-150 C," Fuel Processing Technology, vol. 72, no. 2, pp. 83-101, 2001.

[27] H. Arslan, N. Ozpozan, and T. Ozpozan, "Thermal studies of ptoluidino-p-chlorophenylglyoxime and of some corresponding $\mathrm{Ni}(\mathrm{II}), \mathrm{Cu}(\mathrm{II})$ and $\mathrm{Co}(\mathrm{II})$ complexes," Thermochimica Acta, vol. 329, no. 1, pp. 57-65, 1999. 

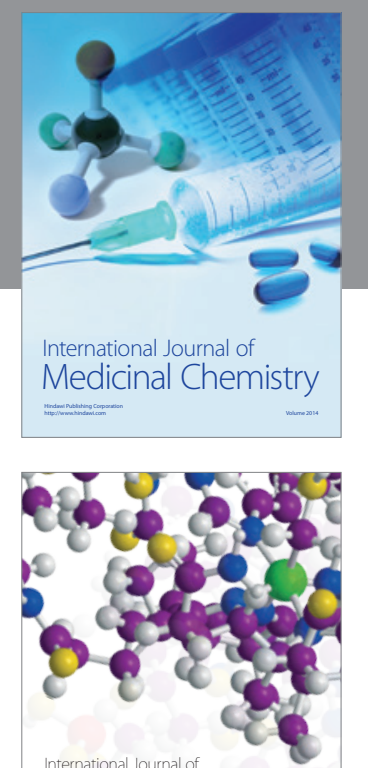

\section{Carbohydrate} Chemistry

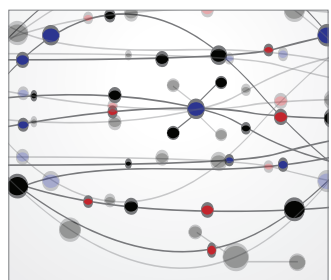

The Scientific World Journal
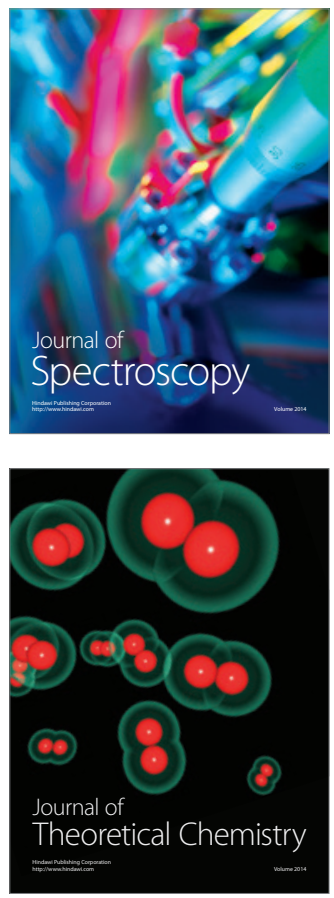
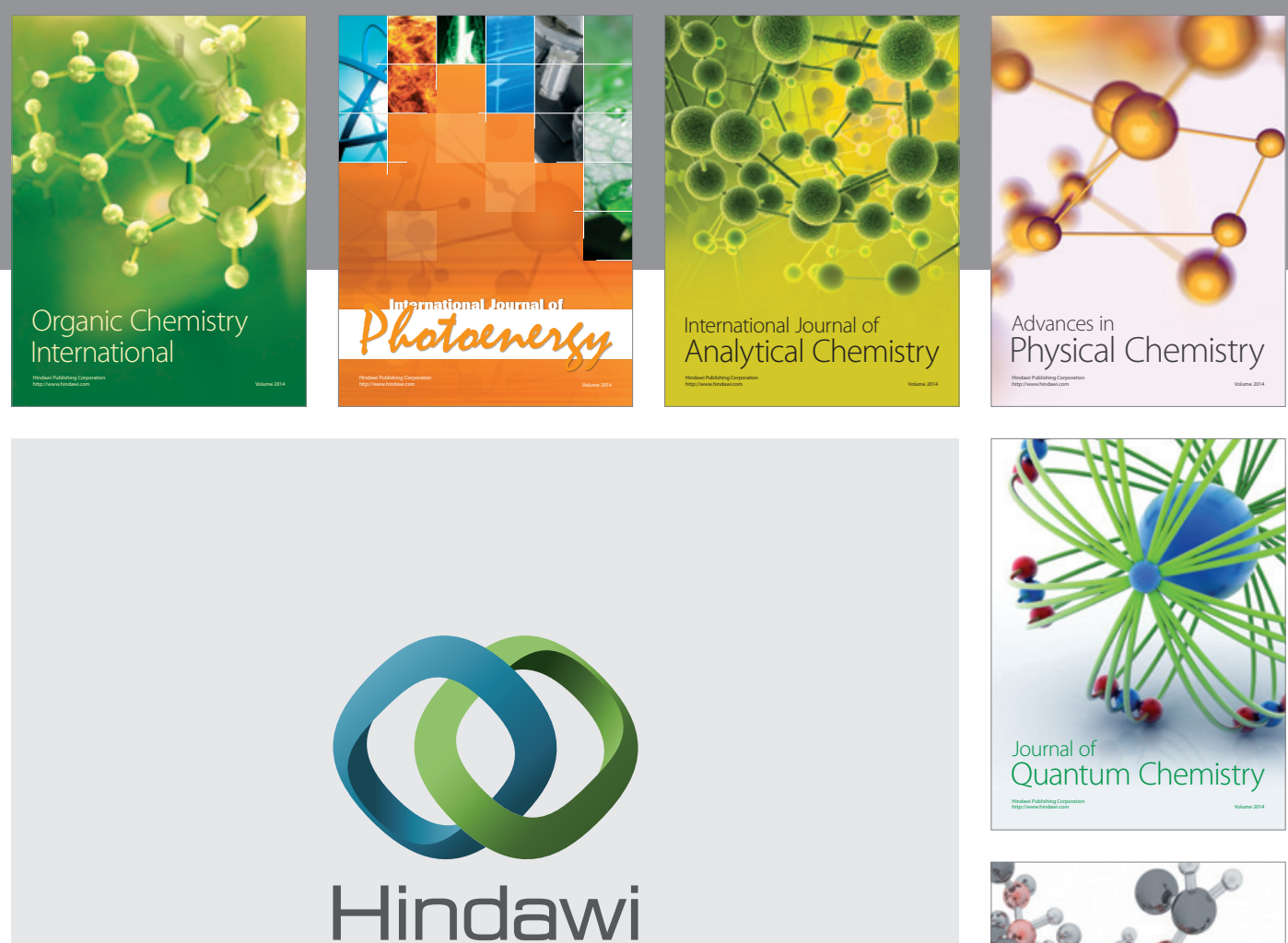

Submit your manuscripts at

http://www.hindawi.com

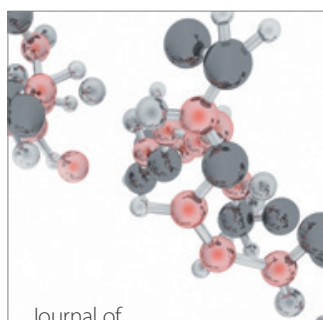

Analytical Methods

in Chemistry

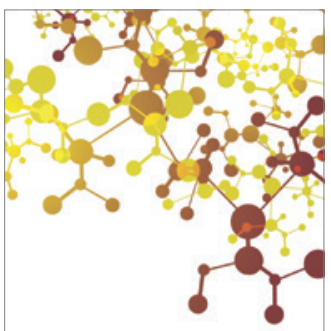

Journal of

Applied Chemistry

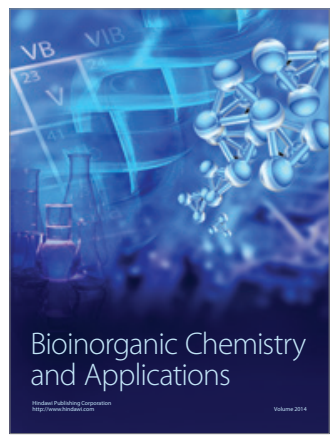

Inorganic Chemistry
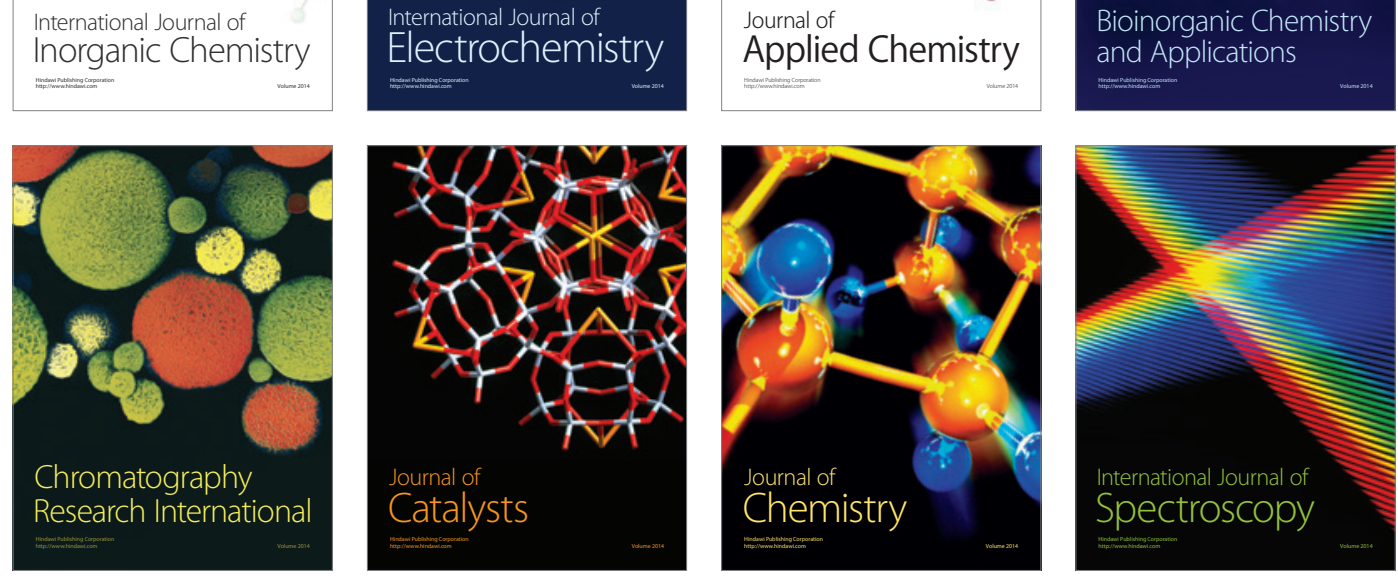